\title{
Variation of digital palpation pressure used in the clinical examination of TMJ disorders and orofacial pain
}

\author{
Variação da aplicação da força de palpação digital utilizada no exame clínico de disfunção \\ temporomandibular e dor orofacial
}

Camilo Massa Ferreira LIMA ${ }^{1}$

Luciane Lacerda Franco Rocha RODRIGUES²

Marcelo Lucchesi TEIXEIRA ${ }^{3}$

Antonio Sérgio GUIMARÃES ${ }^{4}$

\section{ABSTRACT}

\section{Objective}

The present research aims to evaluate the calibration of digital palpation pressure as well as to assess the inter-examiner variation and mean pressure used by a sample consisting of 56 professionals of the TMJ disorders and Orofacial Pain area.

\section{Methods}

Each participant was asked to press a digital balance to approach $1.0 \mathrm{~kg}$ and subsequently $0.5 \mathrm{~kg}$ without seeing the display, in order to obtain a blind data. The values of $1.0 \mathrm{~kg}$ and $0.5 \mathrm{~kg}$ are recommended by the Research Diagnostic Criteria for Temporomandibular Disorder in the refined Axis I, the Physical Assessment. Participants were considered calibrated when they applied the correct pressure in at least 4 of the 5 measurement taken; within a 20\% variation interval (pressures between 0.4 and $0.6 \mathrm{~kg}$ were acceptable for the reference value of $0.5 \mathrm{~kg}$ and between 0.8 and $1.2 \mathrm{~kg}$ for the reference value of $1.0 \mathrm{~kg})$. The $t$-student test was used to analyze data $(p \leq 0.05)$.

\section{Results}

$70 \%$ of the sample was classified as non-calibrated for the $0.5 \mathrm{~kg}$ pressure while $57 \%$ were not calibrated for the $1.0 \mathrm{~kg}$ pressure. The mean inter-examiner variations, $0.3 \mathrm{~kg}$ for the pressure set at $0.5 \mathrm{~kg}$ and $0.6 \mathrm{~kg}$ for the pressure set at $1.0 \mathrm{~kg}$, were considered high.

\section{Conclusion}

The mean pressures applied by participants $(0.7 \mathrm{~kg}$ for joint palpation and $1.4 \mathrm{~kg}$ for muscle palpation) were also considered high in comparison with those recommended by the Research Diagnostic Criteria for Temporomandibular Disorder, but acceptable according to the tendency of applying higher values of $1.0-1.5 \mathrm{~kg}$, as proven by recent study.

Indexing terms: Diagnosis. Palpation. Research. Temporomandibular joint dysfunction syndrome.

\section{RESUMO}

\section{Objetivo}

Avaliar a calibração da força de palpação digital, bem como determinar a variação intra-examinador e a força média aplicada por uma amostra composta de 56 profissionais que atuam na especialidade de disfunção temporomandibular e dor orofacial.

\section{Métodos}

Foi solicitado a cada participante que pressionasse o centro de uma balança digital, sem visualizar o display, o valor que acreditasse ser correspondente à $1,0 \mathrm{~kg}$ e, posteriormente, a $0,5 \mathrm{~kg}$, recomendados pelo protocolo de exame físico do Eixo I do Consortium, the Research Diagnostic Criteria for Temporomandibular Disorders. Foram considerados calibrados aqueles que aplicassem a força correta, aceitando-se uma variação de $20 \%$ (entre 0,4 e 0,6 kg para o menor valor e 0,8 a $1.2 \mathrm{~kg}$ para o maior valor), em 4 das 5 aferições realizadas. Na análise dos dados foi utilizado o teste te Student $(p \leq 0,05)$.

\section{Resultados}

$70 \%$ da amostra foi classificada como não calibrada para a força de 0,5 kg e 57\% não calibrada para 1,0 kg. A variação média intraexaminador de 0,3 kg para o peso de 0,5 kg e 0,6 kg para o de 1,0 kg foram consideradas altas.

\section{Conclusão}

A força média aplicada pelos participantes (0,7 kg para palpação articular e $1.4 \mathrm{~kg}$ para palpação muscular) foi maior que o recomendado pelo Consortium, the Research Diagnostic Criteria for Temporomandibular Disorders, entretanto encontra-se de acordo com a tendência em aplicar valores mais altos entre 1,0 e 1,5 kg, validado em estudo recente.

Termos de indexação: Diagnóstico. Palpação. Pesquisa. Síndrome da disfunção da articulação temporomandibular.

\footnotetext{
${ }^{1}$ Centro de Excelência Odontológica. Av. Conselheiro Rosa e Silva, 1460, Salas 101/102, Empresarial ETC, Recife, PE, Brasil. Correspondência para / Correspondence to: CMF LIMA. E-mail: <camilomassa@ortodontista.com.br>.

${ }^{2}$ Faculdade São Leopoldo Mandic, Curso de Odontologia, Programa de Pós-Graduação em Disfunção Temporomandibular/Dor Orofacial. Campinas, SP, Brasil.

${ }^{3}$ Faculdade São Leopoldo Mandic, Curso de Odontologia, Programa de Pós-Graduação em Prótese Dentária. Campinas, SP, Brasil.

${ }^{4}$ Universidade Federal de São Paulo, Departamento de Morfologia, Disciplina de Anatomia Descritiva e Topográfica. São Paulo, SP, Brasil.
} 


\section{INTRODUCTION}

Safe and valid diagnosis is prerequisite for proper treatment of the disease and the reliability of this diagnosis is also important for the accuracy of the results of epidemiological studies ${ }^{1}$, foundation in which clinical decisions should be supported within the current and ethical context of the Evidence-Based Dentistry (EBD).

Of the three signs comprising the diagnosis of temporomandibular dysfunction, the pains in the masticatory muscles or in the temporomandibular joint are the symptoms most commonly reported by patients. Undoubtedly the manual palpation is the clinical method more used to evaluate pain in these regions of the face; however, the variation in pressure applied for different examiners has been the reason of many mistakes in TMJ dysfunction diagnosis. Thus, according to various authors ${ }^{2-5}$, the digital palpation calibration is crucial to increase the reliability of results.

The training program described by the International Consortium for RDC/TMD - based Research ${ }^{6}$, designed to attest the calibration of dentists, requires complex logistic as it is necessary the presence of a Gold Standard examiner, significant number of patients and statistical methods to ensure the reliability of results. Therefore, it is difficult to be fully applied into training courses.

Because this difficulty, it is possible to find variations in palpation pressure used by dentists during physical examinations, even among experienced professionals, and this certainly affects the reliability of the diagnosis.

This work aims to assess the calibration for the digital palpation pressure $(\mathrm{Kg})$ applied by professionals of the TMJ disorders and Orofacial Pain area by using an electronic digital scale, as well as the variation in pressure among examiners by assessing the pressure at different times and calculating the mean pressure applied by them.

\section{METHODS}

The sample consisted of 56 professionals in training for temporomandibular disorders and orofacial pain, all in the MSc or Specialization levels.

The digital scale (Figure 1), with certificate n. $5289957 / 2009$, was used to assess the palpation pressure of participants. It meets the requirements of the General Coordination for Accreditation of the National Institute of Metrology, Standardization and Industrial Quality (INMETRO) and is recommended by the International Consortium for RDC/TMD - based Research ${ }^{6}$ for pressure calibration.

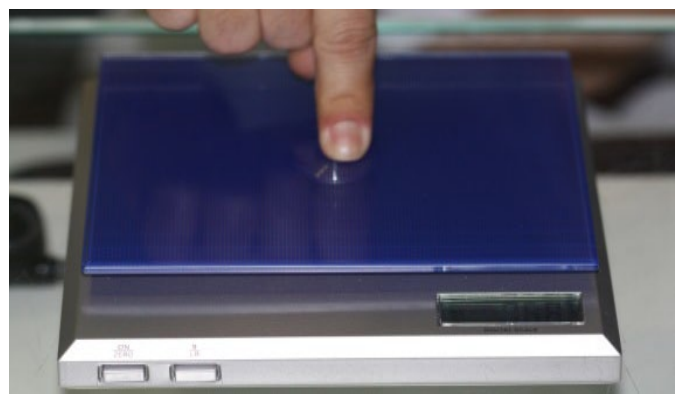

Figure 1. Digital scale.

This digital scale is designed for a measurement range of $0.1-3.0 \mathrm{~kg}$. In the case of an object with weight over this range, the digital scale displays a message indicating that the pressure is over its assessment maximum capacity.

The Research Diagnostic Criteria for Temporomandibular Disorders (RDC/TMD), published by Dworkin \& LeResche7, set a standard for palpation pressure at $1.0 \mathrm{Kg}$ and $0.5 \mathrm{Kg}$ to evaluate the sensitivity of the masticatory muscles and TMJ, respectively. The methodology suggested by studies on training and calibration of palpation pressures ${ }^{8-9}$ was adopted in this study as parameter to attest calibration. Participants who applied the correct pressure in four of five measurements and within a range of $20 \%$ variation were considered calibrated, i.e., $0.4-0.6 \mathrm{~kg}$ are the values acceptable for $0.5 \mathrm{~kg}$ and $0.8-1.2 \mathrm{~kg}$ are the values acceptable for $1 \mathrm{~kg}$. On this way, the participants were placed in a standard position, sitting on a chair in front of the digital scale that was on a table. Then, they were asked, one by one, to press the middle of the digital scale to approach $1.0 \mathrm{~kg}$ with the index finger of the hand of greatest dexterity, without seeing the display. Five measurements for each value were taken in every 3-5 seconds. The same procedure was applied to approach the reference value of $0.5 \mathrm{~kg}$. The participants were oriented to keep pressing the digital scale until the displayed number is stable and the examiner identifies the correspondent value. Importantly, participants were "blind" as to the value shown on the display, only taking notice of this at the end of all measurements.

Absolute distribution, percentages and statistical measures as means, standard deviations, minimum and 
maximum values (descriptive statistics) were used for data analysis. Inferential statistics with a confidence interval was used to mean values and the t-Student test was applied to the sample. Statistical tests were performed at a 95\% confidence interval $(\alpha=0.05)$.

The research project was approved by the Ethics Committee of the São Leopoldo Mandic College, according to protocol n. 2010/0024.

\section{RESULTS}

\section{Results of the applied pressure}

Five measurements were taken for each reference value. The mean values of $0.7 \mathrm{~kg}$ were found to the reference of $0.5 \mathrm{~kg}$ and of $1.4 \mathrm{~kg}$ to the reference of 1.0 $\mathrm{kg}$. The confidence interval for the reference value of 0.5 $\mathrm{kg}$ was $0.6-0.8 \mathrm{~kg}$ and for the reference pressure of 1.0 $\mathrm{kg}$ was 1.2-1.6 kg. In both cases, participants applied pressures exceeding those recommended, although statistically significant $(p<0.001)$.

In the table 1, the mean values for absolute variation were $0.3 \mathrm{~kg}$ for the reference of $0.5 \mathrm{~kg}$ and 0.6 $\mathrm{kg}$ for the reference of $1.0 \mathrm{~kg}$. Minimum and maximum variations were observed for the references values of 0.5 $\mathrm{Kg}(0.03 \mathrm{~min} ; 1.5 \mathrm{max})$ and $1.0 \mathrm{Kg}$ (0.08 min; $2.0 \mathrm{max})$.

Table 1. Mean, standard deviation, confidence interval, p-value, means of absolute variation, minimum and maximum of the five measurements of the pressures of 0.5 and $1.0 \mathrm{~kg}$

\begin{tabular}{lcc}
\hline & \multicolumn{2}{c}{ Pressure } \\
\hline Statistics & $0,5 \mathrm{~kg}$ & $1,0 \mathrm{~kg}$ \\
\hline Mean $^{(1)}$ & 0,7 & 1,4 \\
Standard deviation $^{(1)}$ & 0,4 & 0,7 \\
IC 95\% (1) & 0,6 a 0,8 & 1,2 a 1,6 \\
P-value $^{(2)}$ & $\mathrm{p}^{(2)}<0,001^{*}$ & $\mathrm{p}^{(2)}<0,001^{*}$ \\
Mean of absolute variation $^{(1)}$ & 0,3 & 0,6 \\
Minimum variation $^{(1)}$ & 0,03 & 0,08 \\
Maximum variation $^{(1)}$ & 1,5 & 2,0 \\
\hline
\end{tabular}

Note: $\left.{ }^{*}\right)$ Significant difference at 5.0\%. ( $\left.\leq \leq 0.05\right)$; (1) Measures in kg or kilogram; (2) Student's t test.

\section{Results of the sample calibration}

The participants were considered calibrated when applied pressure close to the reference value, within $20 \%$ variation interval, in at least four of the five measurements. That is, when applied 0.4-0.6 kg to approach the reference pressure of $0.5 \mathrm{~kg}$ and $0.8-1.2 \mathrm{~kg}$ to approach the reference of $1.0 \mathrm{~kg}$. It was observed a high percentage of non- calibrated participants; $70 \%$ for the reference pressure of $0.5 \mathrm{~kg}$ and $57 \%$ for the reference of $0.5 \mathrm{~kg}$ (Table 2).

Table 2. Frequency of the calibration assessments including the five measurements for the pressures of 0.5 and $1.0 \mathrm{~kg}$.

\begin{tabular}{lllll}
\hline \multirow{2}{*}{ Pressure } & \multicolumn{4}{c}{ Calibration results } \\
\cline { 2 - 5 } & \multicolumn{3}{c}{ Calibrated } & \multicolumn{2}{c}{ Non-calibrated } \\
\cline { 2 - 5 } & $\mathrm{n}$ & $\%$ & $\mathrm{n}$ & $\%$ \\
\hline $0,5 \mathrm{~kg}(0.4-0.6)$ & 17 & 30.0 & 39 & 70.0 \\
$1,0 \mathrm{~kg}(0.8-1.2)$ & 24 & 43.0 & 32 & 57.0 \\
\hline
\end{tabular}

Shaefer et al. ${ }^{10}$ validated the value of 2.5 pound $(1.1 \mathrm{~kg})$ for palpation of temporomandibular joint. In recent study, Schiffman et al. ${ }^{11}$ validated the diagnosis of myofascial pain and arthralgia with palpation pressures ranging from 1.0 to $1.5 \mathrm{~kg}$, considering that it was a dynamic test. The authors found a mean pressure of $1.4 \mathrm{~kg}$ when participants have attempted to reach the reference of 1.0 $\mathrm{kg}$. Then, the calibration of participants was determined to pressures ranging from 1.0 to $1.5 \mathrm{~kg}$. That is, participants were considered calibrated when applied pressures of 1.0$1.5 \mathrm{~kg}$ to reach the reference value of $1.0 \mathrm{~kg}$ in at least four of five measurements. In the total sample, the authors found that $30 \%(n=17)$ of participants are calibrated.

\section{DISCUSSION}

Pain in the masticatory muscles or temporomandibular joint is the most frequent complaint related to temporomandibular disorders ${ }^{12}$. The physical examination protocol indicate the method of the palpation of masticatory muscles and posterior and lateral TMJ ligaments as fundamental to identifying pain in these regions. Due to the importance of the reliability of the diagnosis, several studies highlight the value of training and calibrating professionals in this area.

Dahlstrõm et al. ${ }^{13}$ explained that the difference in palpation pressures used by dentists during exams was the mean reason of the low reliability $(0.23$ ICC) of the diagnosis for myofascial pain found in their study. The high percentage of non-calibrated participants observed in the present study $(70 \%$ to the reference value of $0.5 \mathrm{~kg}$ and $57 \%$ to $1.0 \mathrm{Kg}$ ) corroborates the above assertion.

This high percentage can be explained by the fact that participants had not receive any specific training 
prior to the survey, once the objective of this work was to evaluate how calibrated for clinical routine they were. Then, these results evidence the importance of training and calibrating professionals for a standard palpation pressure by using a digital scale, even those skilled professionals with solid training, as MSc or expertise in temporomandibular disorders and orofacial pain.

Goulet et al. ${ }^{14}$ confirmed the importance of the training with digital scale to find calibration for palpation pressure. The authors evaluated four examiners who received prior training to apply both stronger (1.5$2.1 \mathrm{~kg})$ and weaker $(0.5-1.1 \mathrm{~kg})$ pressures. Then, they were subjected to six weekly tests for calibration where they should hit four of the five measurements taken. Importantly, the participants received the results at the end of each test and if the result was not satisfactory, they should be encouraged to practice exercises with a digital scale. The result of this study showed an excellent mean percentage of hit at $89.5 \%$. In turn, John \& Zwijnemburg ${ }^{9}$ found viability in obtaining calibration from professionals. They conducted a study aiming at attesting the calibration of examiners, and to this end, performed tests in six series of five measurements for the reference values of 0.4 and $0.9 \mathrm{~kg}$. Each participant should hit the values in at least four attempts within a $20 \%$ variation interval (ranging both above and below the reference values). The results confirmed calibration for the four participants. As the work by John \& Zwijnemburg9 ${ }^{9}$, the present study also used a digital scale to evaluate examiners, since the use of algometer is indicated only for testing the pain threshold and tolerance of the patients, which was not the purpose of this research.

The highest percentage of non-calibration found for the reference of $0.5 \mathrm{~kg}(70 \%)$ when compared to that presented for the reference of $1.0 \mathrm{~kg}(57 \%)$ is probably due to the greatest sensitivity set to the first, which allowed a margin of error of $0.2 \mathrm{~kg}$ within a $20 \%$ confidence interval ranging both above and below the reference pressure of $0.5 \mathrm{~kg}$. It means half of that $0.4 \mathrm{~kg}$ of variation allowed for the reference pressure of $1 \mathrm{~kg}$.

With respect to the variation of the applied pressure, the work by John \& Zwijnemburg9 show a variation ranging from 0.7 to $0.9 \mathrm{~kg}$ to the reference pressure of $0.9 \mathrm{~kg}$ and from 0.4 to $0.5 \mathrm{~kg}$ to the reference of $0.4 \mathrm{~kg}$. The small variation of $0.2 \mathrm{~kg}$ to the highest and $0.1 \mathrm{~kg}$ to the lowest values are equal to those found by Goulet et al. ${ }^{8}$ when they evaluate examiners also subjected to prior training. Differently, this present study included 56 participants in a sample where they are not subjected to specific training, whereas in others studies, only four examiners were assessed. Indeed, the mean variations of $0.6 \mathrm{~kg}$ found to the reference of $1.0 \mathrm{~kg}$ and $0.3 \mathrm{~kg}$ to the $0.5 \mathrm{~kg}$ are considered high. The inter-examiners variation of up to $2.0 \mathrm{~kg}$ as well as the portion of $9.3 \%$ of the measurements for the reference value of $1.0 \mathrm{~kg}$ exceeding $3.0 \mathrm{~kg}$ indicates the necessity of training and calibrating examiners. In addition, the variation found in a given participant, of only $0.03 \mathrm{~kg}$ to the pressure of $0.5 \mathrm{~kg}$ and $0.08 \mathrm{~kg}$ to the pressure of $1.0 \mathrm{~kg}$, indicates that higher accuracy can be achieved when an examiner is calibrated.

Goulet et al. ${ }^{14}$ explained the low prevalence of diagnoses of group III (arthralgia) in studies by the amount of false-negative results in clinical trials. The authors call attention to the lack of validation for the use of $0.5 \mathrm{~kg}$ of palpation pressure in the temporomandibular joint examinations and suggest the use of stronger pressures. Lausten et al. ${ }^{15}$ confirmed the low reliability for diagnosis of arthralgia since they applied the RDC/TDM to a sample consisting of 69 patients and found a reliability score of 0.4 for TMJ pain. However, the authors alert to the probability of finding many false-positive results as the palpation pressure randomly increases to $1.5 \mathrm{~kg}$, for example. This fact was already verified by Shaefer et al. ${ }^{10}$ when they tested the validation of different pressures for the diagnosis of joint pain. In their work, an examiner calibrated as the RDC/ TMD examined 30 patients with perfect sensitivity (1.0) but insufficient specificity (0.81) to the reference pressure of 1.4 $\mathrm{kg}$ (3 pounds). The validations found were $81 \%$ sensitivity $(\geq 70 \%)$ and $97 \%$ specificity ( $\geq 95 \%$ ) for the value of 1.1 $\mathrm{kg}$ (2.5 pounds), much better than that low sensitivity of $27 \%$ for $0.4 \mathrm{~kg}$ ( 1 pound) recommended by the RDC/TMD. With respect to muscle palpation, Schiffman et al. ${ }^{16}$ have not find significant differences in variation as the pressure increased from 1.0 to $2.0 \mathrm{~kg}$. However, the sensitivity increased at 0.02 and the specificity decreased at 0.03 , that is, the chance of false-positive diagnostic increased very little when patients answer if they are familiar with the pain.

The Validation Project by Schiffman et al. ${ }^{16}$ used a selected sample consisting of 628 patients to compare the results obtained from the application of the original RDC/TMD with a modified and refined protocol called Axis I, whose major changes are: a) muscle palpation pressure ranging from 1.0 to $1.5 \mathrm{~kg}$, justified by the difficulty of applying an exact value on an exam with movement; b) replacement of the TMJ posterior palpation by the portion surrounding the joint with the same pressure of $1.0-1.5 \mathrm{~kg}$, however, keeping the pressure $0.5 \mathrm{~kg}$ for the lateral pole 
palpation; c) questioning whether the pain reported in the exam is the same as the initial complaint. The result for diagnosis of myofascial pain by the refined Axis I showed excellent sensitivity (0.9) and perfect specificity (1.0), while for the diagnosis of joint pain, the modified protocol increased the sensitivity from the low level of 0.4 suggested by the original RDC/ TMD to the excellent level of 0.9. Despite significant improvement, it is worth mentioning that only 0.1 is related to the increased pressure while the major portion (0.4) is related to the pain reported as familiar by patients. Although the modified protocol for physical examination, somewhat questioned by Dworkin ${ }^{18}$, can be considered valid for the main complaints of TMD patients: myofascial pain (la and lb) and joint pain (IIla and IIIb), its greatest merit seems to be related to the concern in reproducing the same patient's complaint in the physical examination rather than to the increased pressure applied in palpation.

The mean pressure of $0.7 \mathrm{~kg}$ found by approaching the reference value of $0.5 \mathrm{~kg}$ is higher than that defined by the RDC/TMD7 for joint palpation. This difference was significant $(p<0,001)$. However, although the confidence interval $(95 \% \mathrm{Cl})$ for $0.6-0.8 \mathrm{~kg}$ is indicating a tendency of participants in applying a pressure exceeding the recommended, it is not possible to affirm how relevant that practice is, since the values found in this study are not discrepant enough to suggest the probability of a falsepositive diagnosis. In addition, such tendency in applying higher values is supported by some studies designed to evaluate the validation of the palpation pressure as, i.e., the work by Shaefer et al. ${ }^{10}$, which validate the pressure of $1.1 \mathrm{~kg}$ for joint palpation, a value much above that found in the present research. Recently, Schiffman et al.."1 obtained validation for diagnosing arthralgia by keeping the pressure of $0.5 \mathrm{~kg}$ in the lateral pole, but increasing the pressure up to $1.0-1.5 \mathrm{~kg}$ in the region surrounding the temporomandibular joint. These values are also much higher than the results obtained in this present research.

Initially, when participants were asked to apply $1.0 \mathrm{~kg}$ for muscle palpation, the mean value of $1.4 \mathrm{~kg}$, statistically significant $(p<0,001)$, was found above the recommended by the $\mathrm{RDC} / \mathrm{TMD}^{7}$. The confidence interval $(95 \% \mathrm{Cl})$, ranging from 1.2 to $1.6 \mathrm{~kg}$, again affirms the tendency of the sample in applying a pressure exceeding the requested value. After analyzing the study by Schiffman et al. ${ }^{11}$, the worry that these results are possibly affecting the clinic with false-positive diagnosis seems to have no scientific foundation. The authors obtained a reduced specificity of only 0.03 as the palpation pressure increased from 1.0 to $1.2 \mathrm{~kg}$, since it is questioned whether the pain is related to the patient's complaint. The mean value of $1.4 \mathrm{~kg}$ is, anyway, within the interval of $1.0-1.5 \mathrm{~kg}$ that is valid for myofascial pain and arthralgia. The reason for $70 \%$ of participants be considered non-calibrated within the interval of $1.0-1.5 \mathrm{~kg}$ (pre-defined by the refined Axis I) is that they were not asked to attempt pressures within such interval, but to hit the reference value of $1.0 \mathrm{~kg}$.

Finally, it's worth mentioning the limitation of this study in evaluating the calibration of pressure applied by examiners in lab environment. The clinical relevance of these findings is questionable, since the static pressure applied in a hard surface like a table with a digital scale is evidently different from the dynamic process corresponding to the physical examinations with palpation of soft tissues, like skins and muscles inserted into the bone tissues.

\section{CONCLUSION}

According to the results obtained in this present research, it is possible to conclude that for the reference value of $0.5 \mathrm{~kg}, 70 \%$ of the sample was considered noncalibrated and for the reference value of $1.0 \mathrm{~kg}, 57 \%$ of participants were classified as non-calibrated. The inter-examiner variations of $0.3 \mathrm{~kg}$ for the reference of $0.5 \mathrm{~kg}$ and of $0.6 \mathrm{~kg}$ for the reference of $1.0 \mathrm{~kg}$ were considered high. The mean pressure of $0.7 \mathrm{~kg}$ applied by participants was higher than the requested value and than that recommended by the RDC/TMD for joint palpation, corroborating the highest values validated by other studies. Meanwhile, the mean pressure of $1.4 \mathrm{~kg}$ was higher than that recommended by the RDC/TMD for muscle palpation, but still within the variation range of $1.0-1.5 \mathrm{~kg}$, which was recently validated.

\section{Collaborators}

CMF LIMA was responsible for describing the methodology, sending the digital scale to accreditation by INMETRO, conducting the lab-work as well as the data collection, and writing the article. LLFR RODRIGUES and ML TEIXEIRA oriented the writing and refinements of the article. AS GUIMARÃES supervised the study and was responsible for defining the methodology and statistical analysis used in this research. 


\section{REFERENCES}

1. Leher A, Kathrin G, Rammelsberg P. Is there a difference in the reliable measurement of the temporomandibular disorder signs between experienced and inexperienced examiners. J Orofac Pain. 2005; 19(1):58-64.

2. Carlsson GE, Magnusson T, Guimarães AS. Tratamento das disfunções temporomandibulares na clínica odontológica. São Paulo: Quintessence; 2006.

3. Hassel AJ, Rammelsberg $P$, Schmitter $M$. Inter-examiner reliability in the clinical examination of temporomandibular disorders: influence of age. Community Dent Oral Epidemiol. 2006;34(1):41-6. doi: 10.1111/j.1600-0528.2006.00250.x.

4. List T, John MT, Dworkin SF, Svensson P. Recalibration improves inter-examiner reliability of TMD examination. Acta Odontol Scand. 2006;64(3):146-52. doi: 10.1080/00016350500483137.

5. Gomes MB, Guimarães JP, Guimarães FC, Neves ACC. Palpation and pressure pain threshold: reliability and validity in patients with temporomandibular disorders. Cranio. 2008;26(3):202-10.

6. International Consortium for RDC/TMD-based research [cited 2012 Nov 3]. Available from: <http://www.rdc-tmdinternational. org $>$.

7. Dworkin SF, LeResche L. Research diagnostic criteria for temporomandibular disorders. J Craniomandib Disord. 1992;6(4):301-55.

8. Goulet JP, Clark GT, Flack VF. Reproducibility of examiner performance for muscle and joint palpation in the temporomandibular system following training and calibration. Community Dent Oral Epidemiol. 1993;21(2):72-7

9. John MT, Zwijnemburg AJ. Interobserver variability in assessment of signs of TMD. Int J Prosthodont. 2001;14(3):265-70.

10. Shaefer JR, Jackson DL, Schiffman EL, Anderson QN. Pressurepain thresholds and MRI effusions in TMJ arthralgia. J Dent Res. 2001;80(10):1935-9. doi: 10.1177/00220345010800101401.

11. Schiffman EL, Truelove EL, Ohrbach R, Tai F, Anderson GC, Pan $W$, et al. The research diagnostic criteria for temporomandibular disorders. V: methods used to establish and validate revised axis I diagnostic algorithms. J Orofac Pain. 2010;24(1):63-78.
12. Manfredini D, Guarda-Nardini L, Winocur E, Piccotti F, Ahlberg J, Lobbezoo F. Research diagnostic criteria for temporomandibular disorders: a systematic review of axis I epidemiologics finding. Oral Surg Oral Med Oral Pathol Oral Radiol Endod. 2011;112(4):453-62. doi: doi: 10.1016/j.tripleo.2011.04.021.

13. Dahlström L, Keeling SD, Fricton JR, Hilsenbeck SG, Clark GM, Rugh JD. Evaluation of a training program intended to calibrate examiners of temporomandibular disorders. Acta Odontol Scand. 1994;52(4):250-4.

14. Goulet JP. Validity of the research diagnostic criteria for temporomandibular disorders axis I in clinical and research settings. J Orofacial Pain. 2009;23(1):17-9.

15. Lausten LL, Glauros AG, Wiliams K. Inter-examiner reliability of physical assessment methods for assessing temporomandibular disorders. Gen Dent. 2004;52(6):509-13.

16. Schiffman EL, Truelove EL, Ohrbach R, Anderson GC, John MT, List $\mathrm{T}$, et al. The research diagnostic criteria for temporomandibular disorders. I: overview and methodology for assessment of validity. J Orofac Pain. 2010;24(1):7-24.

17. Dworkin SF. Research diagnostic criteria for temporomandibular disorders: current status and future relevance. J Oral Rehabil. 2010;37(10):734-43. doi: 10.1111/j.1365-2842.2010.02090.x.
Received on: 7/3/2012

Final version resubmitted on: 3/9/2013 Approved on: 4/10/2013 